\title{
PHASES OF ECONOMIC DEVELOPMENT IN AN ENDOGENOUS GROWTH MODEL WITH INNOVATION AND EDUCATION
}

\author{
Ibtissem Aribi*, Lobna Ben Hassen \\ Department of Economics, Faculty of Economics and Management, University of Sfax, \\ Sfax, Tunisia. \\ Ibtissemaribi87@gmail.com \\ lobna.benhassen@fsegs.rnu.tn
}

\begin{abstract}
This paper analyzes the transitional dynamics of an endogenous growth model with physical capital, human capital and $R \& D$ in which both human capital and innovation drives long run growth. The model suggests that the developing economy follows different stages of development. The first phase is characterized by physical capital accumulation. At the second stage, human capital accumulation represents the main engine of long run growth. The third phase is identified by an increasing variety of intermediate good originating from innovation. However, innovation is not assured for poor economies. In this case, permanent support for innovation can lead a sustainable exit from poverty trap.
\end{abstract}

Keywords: development, innovation, human capital, transitional dynamics.

JEL Classification: $03, \mathrm{O} 31, \mathrm{O} 33, \mathrm{O} 4$.

\section{Introduction}

The determinants of sustainable economic growth are at the center of the very latest economic debates. Although the bulk of the theoretical literature has treated physical capital accumulation, knowledge formation and R\&D-based technological progress as the three key drivers of economic growth. The first strand of analysis considers that physical capital accumulation and exogenous technological change account for much of increase in economic growth rates (Solow, 1956). The second strand of analysis assumes that capital accumulation is the main engine of economic development (Lucas, 1988). The third strand of analysis sees economic development as the result of technological innovation that result from intentional investment decisions made by profit maximizing agents (Romer, 1990 and Grossman and Helpman, 1991).

In this line, it is expedient mentioning that the most of theoretical contributions have treated R\&D-based technological progress and knowledge formation-based growth as separately. As a notable exception, Funke and Strulik (2000) have triggered a vivid line of research by putting forward a unified growth model with physical capital, human capital and R\&D. Funke and Strulik (2000) have assumed that economy passes through different phases of development. In the fully industrialized phase, innovation and education act jointly. Funke and Strulik (2000) present, therefore, a new theory of development in which the increasing pace of technological progress favors the demand for skilled labor in the industrial sector.

\footnotetext{
* Corresponding author: Ibtissem Aribi Cite as:

Aribi, I. and Ben Hassen, L., 2021. Phases of Economic Development in an Endogenous Growth Model with Innovation and Education. Oradea Journal of Business and Economics, 6(2), pp. 78- 87. http://doi.org/10.47535/19910ibe131
} 
Since then, the research by Funke and Strulik (2000) has opened the horizon to several extensions. Gomez $(2005 ; 2008)$ has analyzed the equilibrium dynamics of this model. Sequeira (2008) has developed an endogenous growth model whose originality is to incorporate an erosive effect of human capital by the fact that technological progress generates a depreciation of a certain type of human capital. Gomez (2011) has presented an extended endogenous growth model in which he incorporated an externality in the R\&D sector. This feature of the model proved the existence of an adjustable dynamic in which innovative activities precedes human capital accumulation. lacopetta (2010) has established a unified endogenous growth model that can generate a growth path in which R\&D precedes human capital accumulation. Finally, lacopetta (2011) has presented a unified endogenous growth model based on long-run U.S. data.

With respect to this set of contributions, our model seeks to derive the equilibrium properties of an endogenous growth model in the spirit of Gomez (2005; 2011a; 2011b) and Funke and Strulik (2000). A particularity of this model is to incorporate international R\&D spillovers via the imitation of new foreign technologies. The evolution of the number of patents depends, then, of the number of intermediate goods available at the world frontier. An emerging economy, can therefore make move ahead by assimilating international know and inventing new products.

The remaining of this paper is organized as follows. The next section presents the underlying unified growth model. Section 3 studies the transitional dynamics of the economy. In section 4 , we analyze the equilibrium state, before concluding.

\section{Set up of the model}

Consider the following continuous time model with endogenous economic growth. The long run growth is determined by the interaction of three sectors: sector producing the final good, sector producing the intermediate good and R\&D sector.

\subsection{Individuals and education}

We first describe the household optimization problem. The economy is inhabited by a constant population normalized to unity, of identical individuals who maximize the intertemporal utility function

$$
U_{t}=\int_{0}^{\infty} e^{\rho t} C^{1-\theta} /(1-\theta) \partial_{t}
$$

where $\rho>0$ defines the time preference rate, $0<1 / \theta<1$ denotes the intertemporal elasticity of substitution and $C_{t}$ defines the consumption.

The endowment of time, which is normalized to one, can be divided between spending time in education $u_{E}$, innovating $u_{I}$ and producing $u_{P}, u_{E}+u_{P}+u_{I}=1$

The human capital accumulation is given by

$$
\dot{H}=b\left(u_{E} H\right)^{\varepsilon}{\overline{\left(u_{E} H\right)^{1}}}^{1-\varepsilon}, b>0,0<\varepsilon<1
$$

where $\overline{\left(u_{E} H\right)}$ expresses a specific externality that is associated with the average effective time spent in education. Therefore, we assume the presence of diminishing returns to efficient learning time in education at the private level, combined with an external effect that restores constant returns to scale at the social level.

The intertemporal budget constraint is written; after differentiation with respect to time

$$
\dot{A}=r A+w\left(1-u_{E}\right) H-C
$$


denotes the return per unit of aggregate wealth $A$ and $w$ denotes the wage rate per unit of human capital employed.

Let defines $g_{X}$ the growth rate of $X, g_{X}=\dot{X} / X$. The representative agent maximizes their intertemporal utility (1) subject to their budget constraint (3) and the human capital accumulation (2). The first-order conditions give

$$
\begin{aligned}
& g_{c}=(r-\rho) / \theta \\
& r-g_{w}=b \text { and } u_{E}>0
\end{aligned}
$$

in an equilibrium with education, or

$$
r-g_{w}>b \varepsilon \text { and } u_{E}=0
$$

\subsection{Production and innovation}

There is one final good, which is produced by a Cobb-Douglas technology. The inputs are physical capital $K$, human capital $H$ and a continuum of intermediate goods indicated by $i \in$ $[0, n]$. Production requires the consumption at each time of a quantity of each intermediate input such that the increase of their number raises overall productivity. This property is expressed by an index of differentiated inputs,

$$
D_{t}=\left(\int_{0}^{n} x_{i}^{\gamma} \partial_{i}\right)^{\frac{1}{\gamma}}
$$

which enters as a factor in the production function

$$
Y_{t}=K_{t}^{\beta} D_{t}^{\alpha}\left(u_{p} H_{t}\right)^{1-\alpha-\beta}
$$

Physical capital is used only in the production of the final good. To simplify the analysis, we assume a total depreciation of capital, $\dot{K}=Y-C-\int_{0}^{n} x_{i}$.

The market for final goods is composed of infinite numbers of firms acting in perfect competition and the final good price is normalized to unity. Profit maximization gives the factor demands

$$
\begin{aligned}
& r=\beta \frac{Y}{K} \\
& w=(1-\alpha-\beta) \frac{Y}{u_{p} H} \\
& p_{i}=\alpha x_{i}^{\gamma-1} \frac{Y}{D^{\gamma}}
\end{aligned}
$$

where $p_{i}$ is the price of intermediate good $i$.

The designs of complementary intermediate goods are produced in the R\&D sector. $n$ is used interchangeably for the number of intermediate goods and the stock of knowledge. Invention of new intermediates is assumed to develop according to

$$
\dot{n}=\delta\left(u_{I} H\right){\overline{\left(u_{I} H\right)}}^{\lambda-1} n^{\phi} \overline{(n)}^{\sigma}
$$

where $\delta>0,0 \leq \phi<1,0<\lambda<1$ and $0 \leq \sigma<1, \overline{\left(u_{I} H\right)}$ defines as the average human capital devoted to innovation. The third term in Eq. (12) incorporates a duplication externality of research effort that reflects the idea that inexperienced researchers are working similar problems.

The fourth term in Eq. (12) indicates that the invention of new intermediates depends on the number of intermediate goods that are available on the world frontier. The parameter $\sigma$ is assumed less than unity to capture the fact that the growth rate of path of technology at the 
world frontier leads to a decrease in the marginal benefits for domestic imitation. We assume that the growth rate of $\bar{n}$ is exogenous and is given by

$$
g_{\dot{\bar{n}}}=\dot{\bar{n}} / n=\zeta, \quad \zeta>0
$$

There is monopolistic competition in the R\&D sector and one unit of $Y$ produces one unit of intermediate goods $x_{i}$. Each firm, in this sector, owns an infinite patent for selling its variety $x_{i}$ and maximizes operating profits $\Pi_{i}=\left(p_{i}-1\right) x_{i}$. Facing the price elasticity of demand for intermediates $1 / 1-\gamma$, firms charge a constant markup price $p_{i}=1 / \gamma$.

Since both technology and demand are the same for all intermediate goods, the quantity supplied is the same for all goods, $x_{i}=x, p_{i}=p=1 / \gamma$. Hence, the market-clearing quantity is $x n=\alpha \gamma Y$ and firms' profits are

$$
\Pi=\frac{(1-\gamma) \alpha}{n} Y
$$

and $D=x n^{1 / \gamma}=n^{1-\gamma / \gamma} \alpha \gamma Y$. Substituting this expression into the production function (8), yields

$$
Y^{1-\alpha}=(\alpha \gamma)^{\alpha} K^{\beta} n^{\alpha(1-\gamma) / \gamma}\left(u_{p} H\right)^{1-\alpha-\beta}
$$

Let denote $v$ the present value of the stream monopoly profits from innovation, where $v=\int_{t}^{\infty} e^{-[R(\tau)-R(t)]} \Pi(\tau) \partial \tau$, with $R_{t}=\int_{0}^{t} r(\tau) \partial \tau$. Log-differentiating this expression gives the no arbitrage condition

$$
g_{v}=\frac{\dot{v}}{v}=r-\frac{\Pi}{v}
$$

Eq. (16) implies that the rate of return is equal to the dividend rate $\Pi / v$ plus the capital gain $\dot{v} / v$. Finally, free entry into the $R \& D$ sector requires

$$
w=\delta\left(\overline{u_{I} H}\right)^{\lambda-1} n^{\phi} \bar{n}^{\sigma} v \text { and } u_{I}>0
$$

in an equilibrium with innovation,

$$
w>\delta\left(\overline{u_{I} H}\right)^{\lambda-1} n^{\phi} \bar{n}^{\sigma} v \text { and } u_{I}=0
$$

Before we proceed with the analysis, we shall take into account that $\overline{u_{I} H}=u_{I} H$. Let us denote $\chi=C / K$ the consumption to physical capital ratio and $\psi=H^{\lambda} n^{\phi} \bar{n}^{\sigma} / n$ the knowledge-ideas ratio. Claims to innovative firms and physical capital are the assets in the economy. Aggregate wealth is then $A=K+n v$. Using Eqs. (3), (9), (14) and (16), we get the economy's resource constraint $K=(1-\alpha \gamma) Y-C$, which can be expressed as

$$
g_{K}=\frac{1-\alpha \gamma}{\beta} r-\chi
$$

From Eq. (4) and using Eq. (17), we get

$$
g_{c}=\left(\frac{1}{\theta}-\frac{1-\alpha \gamma}{\beta}\right) r+\chi-\frac{\rho}{\theta}
$$

Some equations are needed to solve the model. Log-differentiating Eqs. (8), (9) and (15), yields

$$
g_{r}=g_{Y}-g_{K}
$$




$$
\begin{aligned}
& g_{w}=g_{Y}-\left(g_{u_{Y}}-g_{H}\right) \\
& (1-\alpha) g_{Y}=\beta g_{K}+\frac{(1-\gamma) \alpha}{\gamma} g_{n}+(1-\alpha-\beta)\left(g_{u_{P}}-g_{H}\right)
\end{aligned}
$$

Eliminating $g_{Y}$ and simplifying, we get

$$
\begin{aligned}
& g_{r}=-\frac{1-\alpha-\beta}{\beta} g_{w}-\frac{\alpha}{\beta} \frac{1-\gamma}{\gamma} g_{n} \\
& g_{u_{P}}=-\frac{1-\alpha}{\beta} g_{w}+\frac{\alpha}{\beta} \frac{1-\gamma}{\gamma} g_{n}+g_{K}-g_{H}
\end{aligned}
$$

Finally Log-differentiating Eq. (12), yields

$$
g_{g_{n}}=\sigma \zeta+\lambda\left(g_{u_{I}}+g_{H}\right)-(1-\phi) g_{n}
$$

This formulation finds a positive relationship between the evolution of invention patent, $R \& D$ and technology adaption.

\section{Equilibrium dynamics of the economy}

In this section, we first analyze the intermediate development phases of a developing economy. Then, we consider the dynamics of the fully industrial economy with physical capital accumulation, knowledge formation and innovation.

\subsection{Neoclassical growth model}

The economy starts without knowledge formation and innovation $\left(u_{E}=u_{I}=0\right)$. Physical capital is then accumulated as the only growth generating mechanism. The dynamics of the initial neoclassical growth phase, in terms of $r$ and $\chi$ variables, is given by the twodimensional differential equation system

$g_{r}=-\frac{(1-\alpha-\beta)(1-\gamma \alpha)}{\beta(1-\alpha)} r+\frac{1-\alpha-\beta}{1-\alpha} \chi$

$g_{\chi}=\left(\frac{1}{\theta}-\frac{1-\alpha \gamma}{\beta}\right) r+\chi-\frac{\rho}{\theta}$

Eq. (27) results from Eqs. (24) and (25), using Eq. (19) and taking into account that $g_{u_{P}}=$ $g_{n}=g_{H}=0$

Using Eqs. (27), (21) and (22), we find that, due to diminishing marginal returns to physical capital accumulation, the interest rate decreases while the efficient wage increases.

\subsection{The knowledge economy}

If $b \varepsilon>\bar{r}=\rho$, the economy reaches a point at which agents begin to invest in knowledge formation. Education time increases and, ultimately, the economy enters the second phase of development, without innovation $\left(u_{E}=1-u_{Y}, u_{I}=0\right)$.

The dynamics of the knowledge economy, in terms of $r, \chi$ and $u_{P}$, is described by the threedimensional differential equation system

$$
\begin{aligned}
& g_{r}=-\frac{1-\alpha-\beta}{\beta}(r-b \varepsilon) \\
& g_{\chi}=\left(\frac{1}{\theta}-\frac{1-\alpha \gamma}{\beta}\right) r+\chi-\frac{\rho}{\theta} \\
& g_{u_{P}}=\frac{(1-\gamma) \alpha}{\beta} r-\chi-\varepsilon\left(1-u_{P}\right)+\frac{(1-\gamma) b \varepsilon}{\beta}
\end{aligned}
$$

which is obtained from Eqs. (24) and (25), using Eq (5) to substitute $g_{w}$, Eqs. (19) and (2) to substitute respectively $g_{K}$ and $g_{H}$ and taking into account that $g_{n}=0$. 
From Eq. (29), we note that, since $\left(\partial g_{r} / \partial r<0\right)$, the interest rate converges to $b \varepsilon>0$ independently of the remaining dynamics of the system, while using Eq. (5); we note that the growth rate of the wage converges to zero.

\subsection{Growth model with innovation}

If $\rho \geq b \varepsilon$, the household does not train. In this case, the dynamic of the economy is entirely determined by innovation activities. If at the initial sate, the economy is sufficiently endowed with human capital, innovation is undertaken, but with decreasing returns on R\&D investment. Consequently, innovation activities are unprofitable.

The system that drives the dynamics of the economy, in terms of variables $r, \chi, u_{P}$ and $\psi$ can be obtained as:

$$
\begin{gathered}
g_{r}=-\frac{1-\alpha-\beta}{\beta} r-\frac{(1-\alpha-\beta)(\lambda-1) u_{P}}{\beta\left(1-u_{P}\right)} g_{u_{P}}+\left\langle\frac{u_{P}}{1-u_{P}}+\frac{1}{\gamma}-\frac{(1-\alpha-\beta) \phi}{(1-\gamma) \alpha}\right\rangle \\
\quad \times \delta\left({ }^{1} \psi-\frac{(1-\alpha-\beta) \sigma \zeta}{\beta}\right. \\
g_{\chi}=\left(\frac{1}{\theta}-\frac{1-\alpha \gamma}{\beta}\right) r+\chi-\frac{\rho}{\theta} \\
g_{u_{P}}=\frac{\alpha(1-\gamma)\left(1-u_{P}\right)}{\beta\left(1-u_{P}\right)+(1-\alpha)(1-\lambda) u_{P}}\left\langle r+\left(\frac{(1-\alpha) u_{P}}{(1-\alpha-\beta)\left(1-u_{P}\right)}-\frac{(1-\alpha) \phi}{(1-\gamma) \alpha}+\frac{1}{\gamma}\right) \delta\left({ }^{1} \psi\right.\right. \\
\left.\quad-\frac{\beta}{(1-\gamma) \alpha} \chi-\frac{(1-\alpha) \sigma \zeta}{(1-\gamma) \alpha}\right\rangle \\
g_{\psi}=\sigma \zeta-\delta(1-\phi)\left(1-u_{P}\right)^{\lambda} \psi
\end{gathered}
$$

The previous system is obtained as follows. First, log-differentiating the free-entry condition (17) yields $g_{w}=(\lambda-1)\left(g_{u_{I}}+g_{H}\right)+\phi g_{n}+\sigma \zeta$. Then, substituting $g_{v}$ from Eq. (16), $\Pi$ from Eq. (14), $w$ from Eq. (10) and $v$ from Eq. (17), we get

$$
g_{w}=r+(\lambda-1)\left(g_{u_{I}}+g_{H}\right)-\frac{(1-\gamma) \alpha u_{P}}{(1-\alpha-\beta) u_{I}} g_{n}+\phi g_{n}+\sigma \zeta
$$

From Eqs. (24) and (25), substituting $g_{w}$ from Eq. (36), $g_{K}$ from Eq. (19) and $g_{n}$ from Eq. (17) and taking into account that $g_{H}=0, u_{I}=1-u_{P}, g_{u_{I}}=-g_{u_{P}} u_{P} / 1-u_{P}$ and $g_{n}=$ $\delta\left(1+u_{p}\right)^{\lambda} \psi$ we get Eqs. (32) and (34). Log-differentiating the knowledge-ideas ratio we get $\mathrm{Eq}(35)$.

\subsection{The advanced industrialized economy}

If $\lambda<1$, the dynamics of the advanced industrialized economy, in terms of the variables $\mathrm{r}, \chi$, $\psi, u_{P}$ and $g_{n}$, is described by the following system

$$
\begin{aligned}
& g_{r}=-\frac{1-\alpha-\beta}{\beta}(r-b \varepsilon)+\frac{\alpha(1-\gamma)}{\beta \gamma} g_{n} \\
& g_{\chi}=\left(\frac{1}{\theta}-\frac{1-\alpha \gamma}{\beta}\right) r+\chi-\frac{\rho}{\theta} \\
& g_{u_{P}}=\frac{\alpha(1-\gamma)}{\beta} r-\chi-b\left(1-u_{P}-\left(\frac{g_{n}}{\delta \psi}\right)^{1 / \lambda}\right)+\frac{\alpha(1-\gamma)}{\beta \gamma} g_{n}+\frac{(1-\alpha) b \varepsilon}{\beta} \\
& g_{\psi}=\sigma \zeta+\lambda b\left(1-u_{P}-\left(\frac{g_{n}}{\delta \psi}\right)^{1 / \lambda}\right)-(1-\phi) g_{n} \\
& g_{g_{n}}=\frac{\lambda}{1-\lambda}(\lambda \sigma \zeta+b \varepsilon)-\frac{\alpha \lambda(1-\gamma)(\delta \psi)^{1 / \lambda} u_{P}}{(1-\lambda)(1-\alpha-\beta)} g_{n}^{1-1 / \lambda}-g_{n}+\frac{\phi}{1-\lambda} g_{n}
\end{aligned}
$$

To obtain this system, we have used that $u_{E}=1-u_{P}-u_{I}$ and $u_{I}=\left(g_{n} /(\delta \psi)\right)^{1 / \lambda}$. Eq. (37) results from Eqs. (24) and (5). From Eqs. (25) and (5), using Eqs. (19) and (2), we get Eq. (39). From $g_{\psi}=\sigma \zeta+\lambda g_{H}-(1-\phi) g_{n}$, using Eq. (2), we obtain Eq. (40). Finally, Eq. (41) results from Eqs. (26), (36) and (5), using Eq. (2).

If $\lambda=1$, from Eqs. (36) and (5), using Eq. (17), we get 


$$
u_{P}=\frac{(1-\alpha-\beta)}{(1-\gamma) \alpha(\delta \psi)^{1 / \lambda}}\left(\sigma \zeta+b \varepsilon+\phi g_{n}\right)
$$

From $g_{u_{P}}=g_{n}-g_{H}$, using Eqs. (25), (19) and (5), we obtain

$$
g_{n}=\frac{\gamma(\alpha(1-\gamma) r+(1-\alpha) b \varepsilon-\beta \chi)}{\beta \gamma-\alpha(1-\gamma)}
$$

Thus, if $\lambda=1$, the dynamics of the economy is described by the following system

$$
\begin{aligned}
& g_{r}=\frac{1-\alpha-\beta}{\beta}(r-b \varepsilon)+\frac{\alpha(1-\gamma)}{\beta \gamma} g_{n} \\
& g_{\chi}=\left(\frac{1}{\theta}-\frac{1-\alpha \gamma}{\beta}\right) r+\chi-\frac{\rho}{\theta}
\end{aligned}
$$

with $u_{P}$ and $g_{n}$ must be substituted respectively by Eqs. (42) and (43).

\section{Balanced growth equilibrium}

This section establishes the existence and the properties of the balanced growth path. The following two propositions provide our main results, which characterize the balanced growth equilibrium.

Proposition 1. Let $b \varepsilon>\rho$. The economy converges to a unique positive, steady state with positive long-run growth, in which the interest rate is

$$
r^{*}=\frac{(1+M) \theta b \varepsilon-\rho+Z}{(1+M) \theta-1}
$$

the ratio of consumption to physical capital is

$$
\chi^{*}=\left(\frac{1-\alpha \gamma}{\beta}-\frac{1}{\theta}\right) r+\frac{\rho}{\theta}
$$

the long-run growth of intermediates is

$$
g_{n}^{*}=\frac{M \lambda}{(1-\phi)[(1+M) \theta-1]}(b \varepsilon-\rho+Z)
$$

the knowledge-ideas ratio

$$
\psi^{*}=\frac{g_{n}^{*}}{\delta u_{I}^{\lambda}}
$$

the share of labor devoted to production and innovation can be obtained from

$$
\begin{aligned}
& u_{P}^{*}=1-u_{I}^{*}-\frac{g_{H}^{*}}{b} \\
& u_{I}^{*}=\frac{(1-\gamma) \alpha g_{n}^{*}}{(1-\gamma) \alpha g_{n}^{*}+(1-\alpha-\beta)\left[(\lambda-1) g_{H}^{*}+\phi g_{n}^{*}+\sigma \zeta+b \varepsilon\right]}\left(1-\frac{g_{H}^{*}}{b}\right)
\end{aligned}
$$

the long-run growth of human capital is

$$
g_{H}^{*}=\frac{(1-\phi) g_{n}^{*}-\sigma \zeta}{\lambda}
$$

and the long-run growth of income, consumption and physical capital is

$$
g_{Y}^{*}=g_{C}^{*}=g_{K}^{*}=\frac{\sigma \zeta}{M \lambda}+\left(\frac{1}{M}+1\right) g_{H}^{*}
$$


with $M=\gamma(1-\phi)(1-\alpha-\beta) / \alpha \lambda(1-\gamma)$ and $Z=\sigma \zeta \theta / \lambda$

Proposition 2. The system reaches the balanced growth path if and only if the sufficient condition is met

$$
\theta>\frac{1+M\left(1+\frac{\rho}{b \varepsilon}\right)+\Phi}{(1+M)+\Phi}
$$

with $\Phi=\frac{\sigma \zeta}{\lambda b \varepsilon}$

For the interior steady state to be feasible, we must have $u_{P}^{*}>0, u_{I}^{*}>0,0<u_{P}^{*}+u_{I}^{*}<1$, $r^{*}>0, \chi^{*}>0$ and $\psi^{*}>0$. Eqs. (48) and (52) show that condition $0<u_{P}^{*}+u_{I}^{*}=b-g_{H}^{*} / b<$ 1 is satisfied if and only if Eq. (54) holds. Since, from Eq. (54) and assuming $b \varepsilon>\rho$ we have $\theta>1 / 1+M$, Eqs. (48) and (46) entail that $r *>0$ and $g_{n}^{*}>0$. Furthermore, $u_{P}^{*}>$ 0 and $u_{I}^{*}>0$ because $\varepsilon-g_{H}^{*}>0$. Thus, Eq. (49) implies that $\psi^{*}>0$. Finally, the ratio of consumption to capital can be expressed as $\chi^{*}=\frac{(1-\alpha \gamma) r^{*}}{\beta}-g_{k}^{*}>\frac{(1-\alpha \gamma-\beta) r^{*}}{\beta}>0$ if the transversality condition is satisfied. Hence, the steady state is feasible.

From Eq. (53), we note that the long-run growth rates of income and consumption depend positively on the quality of education $b$. A higher $b$ induces agents to spend more time in school generating an increase in the level of human capital. Therefore, the increasing pace of human capital formation implies an industrial demand for intermediate goods that stimulated R\&D activities. The economy, moreover, grows fast.

From Eq. (51), we find that an increase in innovation productivity $\delta$ has a positive effect on the steady state shares of time devoted to studying and innovation. Thus, the acceleration of technological progress increases the industrial demand for human capital, which in turn stimulate human capital formation and thus further technological progress. Moreover, innovation share expands hand in hand with educational share.

The effect of externality associated to $R \& D$ on the long-run growth of the subsidy to $R \& D$ is illustrated in Eqs. (48) And (52). An increase in research externalities (an increase of $\phi$ ) generates an increase in the long-run subsidy rate to $R \& D$, while an increase in duplication externalities (an increase of $\lambda$ ) acts in the opposite way.

We suppose that $(1-\alpha-\beta)>0$, following Gomez (2011b). From Eq. (53), we find that the imitation parameter $\sigma$ and the R\&D spillovers $\phi$ act positively on the long-run growth rates of income and consumption. A higher $\sigma$ promotes technology adaption and facilitates the specialization in high quality by promoting the "learning by doing". As the adoption of superior technologies and absorption supplemented by incremental innovation, increase, as the economy grows fast. Nevertheless, the implementation of the advanced technology requires a sufficiently large intermediate good market and a sufficient skill level. Thus, a higher $\phi$ stimulates the growth of developing economies and speeds up convergence. As the technological progress increases, the growth rate of ideas increases generating an industrial demand for human capital that stimulated knowledge formation. Therefore, the economy evolves steadily.

\section{Conclusion}

In this paper, we have understudied the interaction between physical capital accumulation, knowledge formation, innovation and economic growth. The main novelty with respect to previous literature is that the invention of new intermediates depends on the number of intermediate goods available at the world frontier and that innovation is subject to 
externalities in R\&D associated with the duplication of research effort. First, we find that innovation and education share increase jointly along the dynamic transition. The economy starts without knowledge and innovation. Until the second phase of development, the education time increases steadily generating an industrial demand for intermediate goods. Therefore, the size of the intermediate good market and thereby the innovation time rise, first at a slow pace and sharply then, generating an increase in the expected returns on R\&D investment. The economy enters the fully industrialized phase. The acceleration requirements of the industrialization process increase the demand for skilled labor, which in turn increased formal education, and thus technological progress. From that moment, the implementation of the superior technology contributed to economic growth. Then, we provide a sufficient condition to rule out the convergence of the economy to a unique steady state with positive long-run growth.

\section{References}

Arnold, L., 2000. Endogenous growth with physical capital, human capital and product variety: a comment. European Economic Review, 44(8): 1599-1605, https://doi.org/10.1016/S0014-2921(00)00063-5.

Chen, X. and Funke, M., 2013. The Dynamics of Catch Up and Skill and Technology Upgrading in China. Journal of Macroeconomics, 38 , pp. 465-480, https://doi.org/10.1016/i.jmacro.2013.07.002.

Funke, M. and Strulik, H., 2000. On endogenous growth with physical capital, human capital and product variety. European Economic Review, 44(3): 491-515, https://doi.org/10.1016/S0014-2921(98)00072-5.

Gómez, M., 2005. Transitional dynamics in an endogenous growth model with physical capital, human capital and R\&D. Stud Nonlinear Dyn Econom 9(1): Article 5, https://doi.org/10.2202/1558-3708.1240.

Gómez, M.,2008. Fiscal Policy, Congestion, and Endogenous Growth. Journal of Public Economic Theory, 10: Article 4, https://doi.org/10.1111/j.1467-9779.2008.00378.

Gómez, M., 2011 a. Duplication externalities in an endogenous growth model with physical capital, human capital and R\&D. Econ Model 28(1-2): 181-187, https://doi.org/10.1016/..econmod.2010.09.013.

Gómez, M., 2011 b. Stages of Economic Development in an Innovation-Education Growth model. Studies in Nonlinear Dynamics and Econometrics, 15(4), DOI: 10.2202/15583708.1857.

lacopetta, M., 2010. Phases of Economic Development and the Transitional Dynamics of an Innovation-Education Growth Model. European Economic Review, 54 , pp. 317-330, https://doi.org/10.1016/j.euroecorev.2009.06.011

Romer, P., 1986. Increasing Returns and Long-Run Growth. Journal of Political Economy, 94(5): 1002-37, https://www.jstor.org/stable/1833190.

Romer, P., 1987. Growth Based on Increasing Returns Due to Specialization. American Economic Review, 77 , pp. 56-62, https://www.jstor.org/stable/1805429.

Romer, P., 1990. Endegenous Technical Change. Journal of Political Economy, 98(5): 71102, https://www.jstor.org/stable/2937632.

Sequeira, T. N.,2008. Transitional Dynamics of an Endegenous Growth Model with an Erosion Effect. Manchester School, 76 , pp. 436-452, https://doi.org/10.1111/j.14679957.2008.01068.

Sequeira, T. N., 2011. R\&D Spillovers in an endogenous growth model with physical capital, human capital and varieties. Macroeconimc Dynamics, 15, pp. 223-239, http://dx.doi.org/10.1017/S1365100509991155. 
Sequeira, T. N., 2012. Facts and Distortions in an Endegenous Growth Model with Physical Capital and Varieties. Portuguese Economic Journal, 11(3): 171-188, https://doi.org/10.1007/s10258-012-0083-6.

Sequeira, T. N., Santos, M. and Ferreira-Lopes. A., 2017. Income Inequality and Technological Adoption. Journal of Economic Issues, 51(4) , 979-1000, DOI : 10.1080/00213624.2017.1391582.

\section{Bio-notes}

Ibtissem Aribi is a researcher at the Faculty of Economics and Management of Sfax, Tunisia. She has a Ph. D. in Economics at University of Sfax. Her main interests refer to the link between innovation and economic growth.

Lobna Ben Hassen is a professor of economics at the faculty of Economics and Management of Sfax, Tunisia. She is a director of the research master in Money, Financing and Development and a head of the research laboratory CODECI. 